\title{
Epilepsy and quality of life: socio-demographic and clinical aspects, and psychiatric co-morbidity
}

Epilepsia e qualidade de vida: aspectos sociodemográficos, clínicos e comorbidade psiquiátrica

\author{
Gloria Maria de Almeida Souza Tedrus', Lineu Corrêa Fonsecaํ', Rachel Marin Carvalho²
}

\begin{abstract}
Objective: To study socio-demographic and clinical aspects, as well as psychiatric co-morbidity that influence the quality of life of adult epileptic patients. Methods: One hundred and thirty-two individuals diagnosed with epilepsy were evaluated from neurological/clinical and psychiatric points of view and by the Quality of Life in Epilepsy Inventory (QOLIE-31). Predictive factors for the QOLIE-31 scores were studied. Results: The regression analyses indicated the existence of psychiatric co-morbidity (total score, seizure worry, emotional well-being, energy/fatigue, social function and cognitive function) and a greater seizure frequency (total score, cognitive function and energy/fatigue) as predictive factors for lower scores in the total QOLIE-31 score and in various dimensions. Abnormalities in the neurological exam and polytherapy with anti-epileptic drugs were negative factors limited to one of the dimensions cognitive function and social function, respectively. Conclusion: The presence of psychiatric co-morbidity and a greater seizure frequency were the main factors influencing the quality of life in epileptic patients as evaluated by QOLIE-31.
\end{abstract}

Key words: epilepsy, epileptic syndrome, quality of life.

\section{RESUMO}

Objetivo: Estudar os aspectos sociodemográficos, clínicos e comorbidades psiquiátricas que influenciam a qualidade de vida de pacientes adultos com epilepsia. Métodos: Cento e trinta e dois indivíduos com diagnóstico de epilepsia foram avaliados do ponto de vista clínico-neurológico e psiquiátrico e pelo Quality of Life in Epilepsy Inventory (QOLIE-31). Foram estudados os fatores preditores dos escores do QOLIE-31. Resultados: As análises de regressão indicaram a existência de comorbidade psiquiátrica (escore total, crises epilépticas, bem-estar emocional, energia/fadiga, função social e cognição) e a maior frequência de crises (escore total, cognição e energia/fadiga) como fatores preditivos de escores menores no escore total do QOLIE-31 e em várias dimensões. Anormalidade ao exame neurológico e politerapia com drogas antiepiléticas foram fatores negativos limitados a uma das dimensões função cognitiva e função social, respectivamente. Conclusão: A presença de comorbidade psiquiátrica e a maior frequência de crises foram os principais fatores a influenciar a qualidade de vida avaliada pelo QOLIE-31 em pacientes com epilepsia.

Palavras-Chave: epilepsia, síndrome epiléptica, qualidade de vida.

Epileptic patients suffer from prejudice and limitations that can compromise their social integration, and hence present a greater incidence of psychiatric co-morbidities when compared to the general population and to individuals with other chronic diseases ${ }^{1-3}$.

It is known that epilepsy has a great impact on the quality of life (QoL) $)^{4-6}$. However, how the socio-demographic variables, clinical aspects of epilepsy and the psychiatric co-morbidities act on the QoL has still not been completely elucidated, nor which specific domains would be more involved ${ }^{5,7-10}$.
The performance of epileptic individuals is inferior in QoL evaluations and diverges in various aspects from that of individuals with other chronic diseases ${ }^{5,11}$ or from that of the general population ${ }^{6,7,12}$.

Among specific instruments for epilepsy, the Quality of Life in Epilepsy Inventory (QOLIE-31) ${ }^{13}$ is one of the most used instruments, and was validated in 2007 for use in the Brazilian population ${ }^{14}$.

The QoL scales possess a subjective construct and, if evaluated judiciously, can provide contributions for medical orientation and can influence health practices and policies.

Study carried out at Faculdade de Medicina, Pontifícia Universidade Católica de Campinas (PUC-Campinas), Campinas SP, Brazil.

1 Professores de Neurologia, Faculdade de Medicina, PUC-Campinas, Campinas SP, Brazil;

${ }^{2}$ Bolsista de iniciação científica, Fundo de Apoio ao Programa de Iniciação Científica /Reitoria, PUC-Campinas, Campinas SP, Brazil.

Correspondence: Gloria Maria de Almeida Souza Tedrus; Rua Sebastião de Souza 205 / sala 122;13013-173 Campinas SP - Brasil; E-mail: gmtedrus@uol.com.br Conflict of interest: There is no conflict of interest to declare.

Received 08 June 2012; Received in final form 05 December 2012; Accepted 12 December 2012. 
The majority of QoL studies in epilepsy have evaluated patients with refractory epileptic seizures (ES) or with depressive outlooks ${ }^{10,15-17}$ and few have relied on a systematic evaluation of patients with good control of their ES ${ }^{7,18}$.

On the other hand, a better understanding of the QoL in people living in different countries is important, since many cultural, ethnic and economic differences show their impact on the QoL.

Throughout the world there is still a lack of studies identifying which aspects most influence the QoL in adult epileptic individuals, and the results of the existing studies are divergent $^{14,19}$. Recognition of the aspects involved could provide subsidies to improve diagnostic and intervention strategies in the attention given to these patients.

Thus, the objective of this study was to evaluate the perception of QoL in adult epileptic patients, and study the influence of the socio-demographic and clinical aspects of epilepsy and of psychiatric co-morbidities.

\section{METHODS}

\section{Casuistry and procedures}

One hundred and thirty-two consecutive patients from the Outpatient Department of Clinical Neurology of Pontifícia Universidade Católica de Campinas (PUC-Campinas, Brazil) were included, all diagnosed with epilepsy according to the criteria of the 2001 International Classification of Epilepsies and Epileptic Syndromes (ILAE) ${ }^{20}$.

The research was approved by the Ethics Committee for research in human beings of PUC-Campinas, and all the patients signed a term of consent.

Patients with cognitive deficits and difficulty in understanding the QOLIE-31 questions or who had other chronic incapacitating diseases were excluded.

The following procedures were carried out:

1. Anamnesis, to evaluate the socio-demographic (age, gender, schooling, marital status and occupational situation) and clinical data (onset age, type and frequency of ES, duration of epilepsy, use of anti-epileptic drugs AED), besides neurological aspects and epileptic syndrome antecedents;

2. Neurological clinical examination;

3. Collection of data concerning the psychiatric diagnosis carried out in the psychiatric service department, for both the patients who already had psychiatric accompaniment, and those who were referred to it after a neurological consultation, since in the anamnesis they presented complaints or antecedents compatible with psychiatric disturbances;

4. The data of the neuroimaging examination were taken from the hospital records;

5. The QOLIE-31 $1^{13,14}$ was applied. It consists of seven dimensions: seizure worry, overall QoL, emotional well-being, energy/fatigue, cognitive function, medication effects, social function and overall score. The scores vary from 1 to 100, with a higher score indicating a better QoL. The mean application time was 10 minutes.

6. Digital electroencephalogram (EEG) during rest, hyperpnea and photo-stimulation. The EEG recording lasted 20-30 minutes. The presence of alterations in background activity was studied, in addition to the presence of epileptiform activity (EA), its localization and laterality.

\section{Data analysis}

The patients were classified according to the $\mathrm{ILAE}^{20}$ criteria with respect to their epileptic syndrome. Amongst the patients with symptomatic epilepsy, a sub-group was made up of those with temporal lobe epilepsy with hippocampal sclerosis (TLE-HS), characterized according to the clinical aspects and the presence of hippocampal atrophy showed in the brain magnetic resonance imaging, but not submitted to any surgical procedure.

The epilepsy was considered to be under control when there had been no ES in the last 12 months ${ }^{21}$.

The psychiatric diagnosis was made according to the Diagnostic and Statistical Manual of Mental Disorders (DSM-IV) and the International Code of Diseases-10 (ICD-10) criteria. The patients were classified into two groups: with or without psychiatric co-morbidities (only depression or depression associated with other psychiatric diagnoses or only other psychiatric disturbances).

In this study, the term "co-morbidity" was defined as "a medical condition in a patient which causes, is caused by, is related to or simply coexists with the indexed condition" 22 .

The presence of any alteration in the background activity and the presence of EA, as well as its localization and laterality (right, left or bilateral hemispheres), were studied on the EEG.

The criteria proposed for scoring were used in the analysis of the QOLIE- $31^{13}$.

\section{Statistical analysis}

The relationship between socio-demographic and clinical epilepsy aspects and the occurrence of psychiatric comorbidity was studied using the QOLIE-31 data. An independent two-sample $t$-test or ANOVA was used to compare the means with normal distribution, and the Mann-Whitney test was applied for data without normal distribution. The sociodemographic variables were entered in the first block (age, gender, and schooling) and the clinical epilepsy factors, in the second block (onset age and duration of epilepsy, type and frequency of epileptic seizures, epileptic syndrome, neurological examination, background EEG activity, lateralization and localization of the EA). Psychiatric co-morbidity entered in the third regression. The dependent variables were the overall score and the scores of the dimensions. 
The Statistical Package for Social Sciences program (SPSS, version 18.0) was used and the level of significance was $\mathrm{p}<0.05$.

\section{RESULTS}

\section{Socio-demographic and clinical aspects}

Table 1 shows the socio-demographic data of the $132 \mathrm{pa}-$ tients with epilepsy, of which 69 (52.3\%) were of the female gender. The mean age was 43.86 years old and the mean scholastic level was 5.79 years.

Table 1 also shows the clinical data related to seizures (onset age, type, frequency, duration of epilepsy and epileptic syndrome), the finding of an abnormal neurological examination and the number of AED used.

Forty-seven (35.6\%) patients were single, 70 (53\%) were married and 15 (11.4\%) were widowed, divorced or separated. With respect to the occupational situation, 26 (21.6\%) patients were on leave or retired, 52 (43.3\%) worked, $24(20.0 \%)$ were students or housewives and 18 (15\%) were unemployed.

The mean onset age for ES was 22.19 and the mean duration of epilepsy was 21.67 years.

According to the ILAE criteria, 13 cases were classified as idiopathic generalized epilepsies and 67 (50.8\%) and 52 (39.4\%) as symptomatic or probably symptomatic focal epilepsies, respectively. TLE-HS was observed in 40 (30.3\%) cases.

Psychiatric co-morbidity was diagnosed in 71 (53.8\%) patients (Table 1). Depression was the most prevalent psychiatric disturbance, occurring in 39 (20.5\%) patients. Depression was the only psychiatric co-morbidity in 21 (15.9\%) occurrences, and in 18 (13.6\%) cases, it was associated with other psychiatric disturbances. Another psychiatric disturbance not depression - was observed alone in 32 (24.2\%) patients.

\section{QOLIE-31 and its correlation with the socio-demographic and clinical aspects}

The QOLIE-31 scores were significantly lower in females than in males in the dimensions seizure worry, emotional well-being, energy/fatigue, cognitive function and in the overall score (Table 2).

No significant relationship was observed between the QOLIE-31 scores and the onset age of the seizures, duration of the epilepsy, type of ES or epileptic syndrome (Pearson's correlation of ANOVA, $\mathrm{p}>0.05$ ).

There were differences between the groups with respect to the frequency of the seizures for the dimensions energy/ fatigue, cognitive function, social function and overall score, with lower scores for the groups with $>1$ seizure/ 6 months in relation to the other groups (ANOVA, $\mathrm{p}<0.05$ ) (Table 3).

The scores for cognitive function, social function and overall score were significantly lower in patients with focal ES when compared to individuals with generalized tonic-clonic
Table 1. Demographic and clinical characteristics of 132 patients with epilepsy.

\begin{tabular}{|c|c|c|}
\hline Variable & $\begin{array}{c}\text { Number of } \\
\text { occurrences }\end{array}$ & Mean (SD) \\
\hline Age (years) & 132 & $43.86(13.98)$ \\
\hline Schooling (years) & 125 & $5.79(3.77)$ \\
\hline Onset age (years) & 132 & $22.19(15.51)$ \\
\hline Duration & 132 & $21.67(14.01)$ \\
\hline \multicolumn{3}{|l|}{ Gender } \\
\hline Male & 63 & 47.7 \\
\hline Female & 69 & 52.3 \\
\hline \multirow[t]{2}{*}{ Total } & 132 & \\
\hline & & $\%$ \\
\hline \multicolumn{3}{|l|}{ Seizure type } \\
\hline Absence/myoclonic & 13 & 9.8 \\
\hline Complex focal & 89 & 67.4 \\
\hline Simple focal & 14 & 10.6 \\
\hline Generalized tonic-clonic & 16 & 12.1 \\
\hline Total & 132 & 100 \\
\hline \multicolumn{3}{|l|}{ Seizure frequency } \\
\hline seizure free $\geq 1$ year & 58 & 45.0 \\
\hline$\leq 1$ seizure/6 months & 17 & 13.2 \\
\hline$>1$ seizure/6 months & 54 & 41.8 \\
\hline Total & 129 & 100 \\
\hline \multicolumn{3}{|l|}{ Epileptic syndrome } \\
\hline Generalized idiopathic & 13 & 9.8 \\
\hline Symptomatic & 52 & 39.4 \\
\hline Probably symptomatic & 67 & 50.8 \\
\hline Total & 132 & 100 \\
\hline \multicolumn{3}{|l|}{ Neurological examination } \\
\hline Normal & 86 & 65.2 \\
\hline Abnormal & 46 & 34.8 \\
\hline Total & 132 & 100 \\
\hline \multicolumn{3}{|l|}{ Psychiatric co-morbidity } \\
\hline Absent & 61 & 46.2 \\
\hline Present & 71 & 53.8 \\
\hline Total & 132 & 100 \\
\hline \multicolumn{3}{|l|}{ Number of AED } \\
\hline Mono-therapy & 65 & 55.1 \\
\hline Poly-therapy & 53 & 44.9 \\
\hline Total & 118 & 100 \\
\hline
\end{tabular}

SD: standard deviation; AED: anti-epileptic drugs.

ES (59.93 versus 69.10; 70.64 versus 80.93; 59.86 versus 66.39, respectively) (Mann-Whitney test; $\mathrm{p}<0.05$ ).

The patients using mono-therapy with AED, when compared to those using poly-therapy, presented significantly higher scores in the dimensions seizure worry (51.47 versus 42.68; $\mathrm{p}=0.032$ ), social function ( 80.30 versus $65.75 ; \mathrm{p}=0.001$ ) and overall score (65.24 versus 56.16; $\mathrm{p}=0.005$ ) of QOLIE-31.

The scores for the dimensions cognitive function (57.27 versus 67.26; $\mathrm{p}=0.029)$ and social function (67.70 versus 77.06 ; $\mathrm{p}=0.03$ ) of the QOLIE-31 were significantly lower in patients showing alterations in their neurological examinations when compared to those showing no alterations. 
There was no significant difference between the scores for QOLIE-31 and the other aspects studied (alteration in background activity on the EEG, laterality of EA and the epileptic syndrome) ( $t$-test; p>0.05).

The patients with no psychiatric co-morbidity presented significantly higher scores in the QOLIE-31 (overall and dimensions) when compared to those showing psychiatric comorbidities $(\mathrm{p}<0.05)$ (Table 4).

\section{Regression analysis}

Table 5 shows the results of multiple regression analysis for the various QOLIE-31 scores.

The linear regression models indicated that the existence of psychiatric co-morbidity was a predictor for lower scores in the QOLIE-31 for the overall score and the following five dimensions: seizure worry, emotional well-being, energy/ fatigue, cognitive function and social function. Psychiatric co-morbidity was the largest single factor for the prediction of scores in the QOLIE-31.

The seizure frequency was a significant predictor for the dimensions of cognitive function, energy/fatigue and for the overall score, whereas the neurological examination and number of drugs were factors for cognitive function and social function, respectively. Other possible socio-demographic and clinical factors, including those showing significance for QoL in previous specific comparisons, were excluded for not showing significance in the regression analyses, such as gender and type of ES.

\section{DISCUSSION}

\section{QoL and the socio-demographic and clinical aspects}

The present casuistry was constituted of adult patients with focal (symptomatic and probably symptomatic) and

Table 2. Scores in the Quality of Life in Epilepsy Inventory (QOLIE-31) for total sample, women and men.

\begin{tabular}{llccc} 
QOLIE-31 subscales and total & Total sample & Women & Men & p-value \\
\hline Seizure worry & $48.88(22.71)$ & $45.08(22.97)$ & $53.05(21.84)$ & $0.047^{\star}$ \\
Overall quality of life & $48.27(20.57)$ & $45.7(18.79)$ & $51.34(22.11)$ & 0.214 \\
Emotional well-being & $65.52(24.18)$ & $59.54(23.17)$ & $72.06(23.74)$ & $0.001^{\star}$ \\
Energy/fatigue & $58.48(22.70)$ & $54.71(21.50)$ & $62.62(23.42)$ & $0.031^{\star}$ \\
Cognitive function & $62.92(26.12)$ & $58.48(27.33)$ & $67.78(24.01)$ & $0.044^{\star}$ \\
Medication effects & $77.61(24.99)$ & $75.60(27.66)$ & $79.80(21.72)$ & 0.634 \\
Social function & $73.99(23.78)$ & $71.54(24.59)$ & $76.68(22.75)$ & 0.165 \\
Overall score & $61.99(17.37)$ & $58.37(17.31)$ & $65.94(16.67)$ & $0.012^{\star}$ \\
\hline
\end{tabular}

All values are means (standard deviation). Mann-Whitney test; ${ }^{\star} p<0.05$.

Table 3. Scores in the Quality of Life in Epilepsy Inventory (QOLIE-31) and seizure frequency.

\begin{tabular}{lcccc} 
QOLIE-31 subscales and total & Seizure free $\geq 1$ year & $\leq 1$ seizure/6 months & $>1$ seizure/6 months & $p$-value \\
\hline Seizure worry & $51.58(21.87)$ & $49.99(19.51)$ & $46.41(22.56)$ & 0.477 \\
Overall quality of life & $51.29(20.35)$ & $50.24(23.45)$ & $45.41(19.51)$ & 0.300 \\
Emotional well-being & $67.93(25.76)$ & $74.12(24.70)$ & $60.96(21.01)$ & 0.095 \\
Energy/fatigue & $62.07(25.22)$ & $65.00(17.94)$ & $53.15(19.19)$ & $0.049 *$ \\
Cognitive function & $70.16(24.88)$ & $61.86(22.90)$ & $55.45(26.35)$ & $0.010^{*}$ \\
Medication effects & $81.66(24.73)$ & $74.51(27.37)$ & $74.69(24.50)$ & 0.288 \\
Social function & $81.28(20.11)$ & $75.00(22.98)$ & $65.06(25.42)$ & $0.001 *$ \\
Overall score & $66.49(19.09)$ & $64.52(14.69)$ & $56.55(16.83)$ & $0.007 *$ \\
\hline
\end{tabular}

All values are means (standard deviation). ANOVA; ${ }^{*} p<0.05$.

Table 4. Scores in the Quality of Life in Epilepsy Inventory (QOLIE-31) and psychiatric co-morbidity.

\begin{tabular}{lccc}
\multirow{2}{*}{ QOLIE-31 subscales and total } & \multicolumn{2}{c}{ Psychiatric co-morbidity } & p-value \\
\cline { 2 - 3 } & Presence $(n=61)$ & Absence $(n=71)$ & $0.002^{*}$ \\
Seizure worry & $55.48(20.33)$ & $43.22(23.25)$ & $0.029 *$ \\
Overall quality of life & $51.65(17.04)$ & $45.37(22.91)$ & $0.001^{\star}$ \\
Emotional well-being & $72.85(22.44)$ & $59.21(23.99)$ & $0.009^{*}$ \\
Energy/fatigue & $64.18(23.19)$ & $53.59(21.23)$ & $0.000^{\star}$ \\
Cognitive function & $74.22(20.71)$ & $53.21(26.51)$ & $0.026^{*}$ \\
Medication effects & $83.01(22.22)$ & $72.96(26.44)$ & $0.000^{*}$ \\
Social function & $83.15(20.38)$ & $66.13(23.80)$ & $0.000^{*}$ \\
Overall score & $69.82(13.70)$ & $55.26(17.44)$ & \\
\hline
\end{tabular}

All values are means (standard deviation). Mann-Whitney test; ${ }^{\star} p<0.05$. 
Table 5. Multiple regression for the Quality of Life in Epilepsy Inventory (QOLIE-31) scores and predicting variables.

\begin{tabular}{|c|c|c|c|c|}
\hline QOLIE-31 scores & Predicting variables & Coefficient & $95 \% \mathrm{Cl}$ & $\mathrm{p}$-value \\
\hline \multirow[t]{2}{*}{ Overall score } & Psychiatric co-morbidity (yes/no) & -13.217 & $-18.783-7.650$ & 0.000 \\
\hline & Seizure frequency (more than $1 / 6$ months - less) & -7.064 & $-12.700-1.429$ & 0.008 \\
\hline Seizure worry & Psychiatric co-morbidity (yes/no) & -10.456 & $-18.558-2.353$ & 0.012 \\
\hline Overall quality of life & No variables were entered into the equation & & & \\
\hline Emotional well-being & Psychiatric co-morbidity (yes/no) & -13.641 & $-21.684-5.599$ & 0.001 \\
\hline \multirow[t]{2}{*}{ Energy/fatigue } & Psychiatric co-morbidity (yes/no) & -8.430 & $-16.26-0.600$ & 0.035 \\
\hline & Seizure frequency (more than $1 / 6$ months - less) & -8.523 & $-16.45-0.596$ & 0.035 \\
\hline \multirow[t]{3}{*}{ Cognitive function } & Psychiatric co-morbidity (yes/no) & -18.598 & $-26.968-10.229$ & 0.000 \\
\hline & Seizure frequency (more than $1 / 6$ months - less) & -9.925 & $-18.318-1.533$ & 0.021 \\
\hline & Neurological examination (abnormal - normal) & -9.941 & $-18.495-1.387$ & 0.023 \\
\hline Medication effects & Number of anti-epileptic drugs (poly-therapy - mono-therapy) & -9.709 & $-18.676-0.742$ & 0.034 \\
\hline \multirow[t]{2}{*}{ Social function } & Psychiatric co-morbidity (yes/no) & -15.212 & $-23.447-6.977$ & 0.000 \\
\hline & Number of anti-epileptic drugs (poly-therapy - mono-therapy) & -11.112 & $-19.347-2.877$ & 0.009 \\
\hline
\end{tabular}

Cl: confidence interval.

idiopathic generalized epilepsies. Approximately $40 \%$ of the cases had no ES for more than one year.

The majority of studies on QoL found in the literature evaluate patients with uncontrolled epilepsy, candidates for surgery, who frequently show an elevated occurrence of comorbidities and psychosocial difficulties, which could compromise their $\mathrm{QoL}^{12,15,23,24}$.

In the treatment of epileptic patients, the type and frequency of ES, side effects of AED and repercussions of probable cerebral injury ${ }^{5}$ are considered relevant. More recently, the evaluation of the QoL from a wider perspective has been recognized as important, as well as the evaluation of factors that can independently affect the satisfaction with life and contribute to a better understanding of the problems faced by epileptic patients, including those with controlled $\mathrm{ES}^{5,15}$.

In the present study, the mean total score in the QOLIE-31 was similar to that described by Cramer et $\mathrm{al}^{25}$.

There was a greater perception of compromise of the QoL in female individuals, in dimensions of seizure worry, emotional well-being, cognitive function and overall score. Some studies described very low QoL values for female epileptic patients and for females in the general population ${ }^{9,26}$. These lower values could be attributed to different cultures and social support, or could be related to problems with pregnancy and epilepsy ${ }^{6,8}$. However, new studies are required to nullify such questions.

Similarly to some studies ${ }^{10}$, no significant difference was found in the QoL due to the other socio-demographic aspects studied, although other papers ${ }^{5,7-9,15}$ reported that an elevated age and low scholastic level were related to a worse QoL.

In the present study, it was observed that the clinical aspects related to epilepsy (frequency and type of ES, use of poly-therapy with AED and the presence of alterations in the neurological exam) negatively influenced the QoL.

A greater ES frequency exerted a markedly negative influence on the QoL and was a significant predictor for the dimensions of cognitive function, energy/fatigue and overall score, a fact already documented in the literature ${ }^{4-6,9,10,13,16}$. Besides, a sustained improvement in QoL was associated with long-term absolute freedom from $\mathrm{ES}^{4,11}$. Other studies have reported that the QoL of individuals with controlled ES is similar to that of the general population ${ }^{6,11,25,27}$.

As previously described ${ }^{15,16,18}$, it was observed in the present study that an elevated ES frequency and complex focal seizures correlated with lower scores in the QOLIE-31 (overall score and the dimensions of emotional well-being, cognitive and social functions). These findings suggest that the severity of the epilepsy could contribute to social isolation, loss of independence, vocational limitations and other disabilities, with a potentially negative effect on the QoL independently of other aspects, such as the occurrence of psychiatric co-morbidity ${ }^{5,6,13}$.

The patients using single AED presented significantly higher scores in the QOLIE-31 (overall score and the dimensions of seizure worry and social function) when compared to those using poly-therapy. There are disagreements in the literature concerning the influence of the number of AED on the QoL. Some studies describe an association between poly-therapy and a worse QoL ${ }^{10,26,27}$, particularly in the dimension of seizure worry, which represents a concern with the occurrence of ES, apprehension about possible traumatisms and the social effects of the unpredictability of the ES. However, other studies did not observe this association ${ }^{8,16}$. On the other hand, some authors question the ability to evaluate the impact of AED on the QoL, since this aspect has a very small impact on calculation of the scores in the QOLIE- $31^{26}$.

There was no significant correlation between the scores in the QOLIE-31 and other clinical aspects (onset age and time of epilepsy, alteration in background activity, laterality of the EA in the EEG and the epileptic syndrome). These data are in agreement with those of other studies ${ }^{5,24}$. 


\section{Psychiatric co-morbidities and QoL}

Psychiatric co-morbidity was found in $71(54.1 \%)$ patients. According to the literature ${ }^{8,28}$, depression was found in an important proportion of the cases, with slight depressive symptoms predominating. It is known that in epileptic patients, depending on the type of population and the diagnostic instruments used, psychiatric disturbances are prevalent and depression is the most frequent co-morbidity ${ }^{8,17}$.

The presence of psychiatric co-morbidity was the largest independent predictor of low scores in the QOLIE-31 (overall score and dimensions), similarly to the results of previous studies ${ }^{28-30}$.

Depression showed a strong negative impact on the QoL, as well as a significant correlation between the worst scores in the QOLIE-31 (overall score and the dimensions of seizure worry, emotional well-being, energy/fatigue, cognitive and social functions) and a more serious level of depression ${ }^{8,11,17,29}$.

More recently, the importance of other psychiatric comorbidities on the compromise of the QoL has been recognized $^{8,18}$. In the present study, a negative impact of other psychiatric disturbances, other than depression, on the QoL of patients was observed, but in a less accentuated way.

In some studies, the presence of depression has been indicated as an essential factor in the patient's judgment concerning his/her QoL. This can partly be explained by the fact that the QoL inventories reflect the social and psychological domains more, and do not integrate the clinical aspects of epilepsy sufficiently, being thus subjective measures that the individual uses to report on his/her perception of theirQoL ${ }^{10}$.

There are evidences that psychological factors contribute 30 to $35 \%^{8,23}$ or up to $50 \%^{13,15,23,25}$ to the variation in QoL, as compared to values of about $20 \%$ for the clinical variables related to epilepsy. This strong connection between mood and the QoL instruments is well established in the context of other chronic diseases ${ }^{10}$.

\section{Limitations of this study}

The greatest limitation of this study is the fact that it was cross-sectional, and hence the evaluation of the relationship between QoL and the clinical variables related to epilepsy and socio-demographic aspects was carried out in a precise, punctual evaluation, which could present limitations.

In conclusion, there were variable compromises in the different domains of QoL in epileptic patients.

Socio-demographic (female gender) and clinical aspects related to epilepsy (frequency and type of ES, use of polytherapy in AED, and presence of alterations in the neurological examination) negatively influenced QoL in this study.

The presence of psychiatric co-morbidity and a greater seizure frequency were the main factors influencing the QoL as evaluated by the QOLIE-31 in patients with epilepsy.

The study of QoL could provide subsidies to improve diagnostic strategies, research and interventions in the attention given to patients with epilepsy.

\section{References}

1. Gaitatzis A, Carroll K, Majeed A, Sander JW. The epidemiology of the comorbidity of epilepsy in the general population. Epilepsia 2004;45:1613-1622.

2. Swinkels WA, KuykJ, van Dyck R, Spinhoven P. Psychiatric comorbidity in epilepsy. Epilepsy Behav 2005;7:37-50.

3. Tellez-Zenteno JF, Patten SB, Jette N, Williams J, Wiebe S. Psychiatric comorbidity in epilepsy: a population-based analysis. Epilepsia 2007;48:2336-2344.

4. Vickrey BG, Berg AT, Sperling MR, et al. Relationship between seizure severity and health-related quality of life in refractory localizationrelated epilepsy. Epilepsia 2000;4:760-764.

5. Baker GA, Jacoby A, Stalgis C, Monnet D. Quality of the life in people with epilepsy: an european study. Epilepsia 1997;38:3533-3562.

6. Leidy NK, Elixhauser A, Vickrey B, Means E, Willian MK. Seizure frequency and the health-related quality-of-life of adults with epilepsy. Neurology 1999;53:162-166.

7. Berto P. Quality of the life in patients with epilepsy and impact of treatment. Pharmacoeconomics 2002;20:1039-1059.

8. Johnson EK, Jones JE, Seidemberg M, Hermann BP. The relative impact of anxiety, depression, and clinical seizure features on healthrelated quality of life in epilepsy. Epilepsia 2004;45:544-550.

9. Dijibuti M, Shakarishvili R. Influence of clinical demographic and socioeconomic variables on quality of life in patients with epilepsy: finding from Georgian study. J Neurol Neurosurg Psychiatry 2003;74:570-573.

10. Tracy JI, Dechant V, Sperling MR, Cho R, Glosser D. The association of mood with quality of life ratings in epilepsy. Neurology 2007;68:1101-1107.
11. Stavem K, Loge JH, Kaasa S. Health status of people with epilepsy compared with a general reference population. Epilepsia 2000;41:85-90.

12. Villeneuve N. Quality-of-life scales for patients with drug-resistant partial epilepsy. Rev Neurol (Paris) 2004;160:S376-S393.

13. Cramer JA, Perrine K, Devinky O, Brvant-Comstock L, Meador K, Hermann B. Development and cross-cultural translations of a 31item quality of life in epilepsy inventory. Epilepsia 1998;39:81-88.

14. Silva $\mathrm{TI}$, Ciconelli RM, Alonso NB, et al. Validity and reliability of the Portuguese version of the quality of life in epilepsy inventory (QOLIE-31) for Brazil. Epilepsy Behav 2007;10:234-241.

15. Loring DW, Meador KJ, Lee GP. Determinants of quality of life in epilepsy. Epilepsy Behav 2004;5:976-980.

16. Harden CL, Maroof DA, Nikolov B, et al. The effect of seizure severity on quality of life in epilepsy. Epilepsy Behav 2007;11:208-211.

17. Kanner AM, Barry JJ, Gilliam F, Hermann B, Meador KJ. Anxiety disorders, subsyndromic depressive episodes, and major depressive episodes: do they differ on their impact on the quality of life of patients with epilepsy? Epilepsia 2010;51:1152-1158.

18. Jeli L, Tesar G, Obuchowski N, Novak E, Najm I. Quality of life in 1931 adult patient with epilepsy: seizures do not tell the whole story. Epilepsy Behav 2011;22:723-727.

19. Salgado PCB, Cendes F. The effects of epileptic seizures upon quality of life.J Epilepsy Clin Neurophysiol 2009;15:110-113.

20. Engel Jr J. A proposed diagnostic scheme for people with epileptic seizures and with epilepsy: report of the ILAE task force on classification and terminology. Epilepsia 2001;42:796-803.

21. Shorvon SD. Handbook of Epilepsy Treatment. $3^{\text {rd }}$ ed. New York: WileyBlackwell; 2010 
22. Fortin M, Lapointe L, Hudon C, Vanasse A, Ntetu AL, Maltais D. Multimorbidity and quality of life in primary care: a systematic review. Health Qual Life Outcomes 2004;2:51.

23. Boylan LS, Flint LA, Labovitz DL, Jackson SC, Starner K, Devinsky O. Depression but not seizure frequency predicts quality of life in treatment-resistant epilepsy. Neurology 2004;62:258-261.

24. Taylor RS, Sander JW, Taylor RJ, Baker GA. Predictors of health-related quality of life and costs in adults with epilepsy: a systematic review. Epilepsia 2011;52:2168-2180.

25. Cramer JA, Arrigo C, van Hammee G, Gauer LJ, Cereghino JJ. Effect of levetiracetam on epilepsy related quality of life. Epilepsia 2000;41:868-874.
26. Auriel E, Landov H, Blatt I, et al. Quality of life in seizure-free patients with epilepsy on monotherapy. Epilepsy Behav 2009;14:130-133.

27. Suurmeijer TPBM, Reuvekamp MF, Aldenkamp BP. Social functioning, psychological functioning, and quality of life in epilepsy. Epilepsia 2001;42:1160-1168.

28. Gilliam F, Hecimovic H, Sheline Y. Psychiatric comorbidity, health, and function in epilepsy. Epilepsy Behav 2003;4:S26-S30.

29. Kwan P,Yu E, Leung H, Leon T, Mychaskiw MA. Association of subjective anxiety, depression, and sleep disturbance with quality-of-life ratings in adults with epilepsy. Epilepsia 2009;50:1059-1066.

30. Tedrus GMAS, Fonseca LC, Fonseca ALA, Carvalho RM, Oliveira EM. Epilepsia e depressão: aspectos sociodemográficos e clínicos associados. Rev Cienc Med 2009;18:243-250. 